\title{
Poder PRESIDENCIAL LIMITAdo Y OPOSICIÓN ACTIVA COMO REQUISITOS DE LA DEMOCRACIA*
}

ISIDORO CHERESKY**

El régimen democrático establecido en 1983 ha tenido como sustento firme el rechazo a la dictadura militar que le precedió y que culminó un ciclo de poderes dictatoriales y regímenes de dudosa legitimidad. El carácter negativo de la institución de la democracia - dominada por el "nunca más"- es común a las fundaciones de regimenes políticos. Dejaba por delante el afirmar las raices de costumbres e instituciones democráticas.

En la actualidad es más evidente de lo que era en 1983, que entonces no se restauraba un régimen político sino que se emprendía su construcción en base a frágiles experiencias propias, la mayor de las cuales había sido la emergencia de un movimiento de derechos humanos que torció la tendencia de las fuerzas políticas y de una sociedad pasiva a dar vuelta la página sobre lo que durante sus primeros años fue considerado una dictadura más. (1) Por lo demás ya se extendía la ola mundial que llevaria al final de la década a que la democracia se transformara en el régimen por excelencia, o el régimen único lo que constituia una extraordinaria presión para su establecimiento y mantención.

En los años transcurridos se ha consolidado y hasta naturalizado la vida democrática en un punto decisivo. No hay poder político que pueda pretenderse legítimo fuera de su consagración electoral y este enunciado se ha extendido al interior de las fuerzas políticas por medio de prácticas que privilegian la voluntad de la

\footnotetext{
* Una primera versión de este trabajo se presentó en el Seminario La democrucia en Argentina. Evolución y perspectivas, organizado por el Instituto de investigaciones Gino Germani de la Universidad de Buenos Aires y el North South Centre de la University of Miami, el 11 y 12 de julio 1996 en Buenos Aires.
}

** Universidad de Buenos Aires. 
sociedad por sobre la de las propias estructuras partidarias. Y ello se ha producido en detrimento del poder de las corporaciones, incluidas las del poder económico.

Pero, la vida política tiende a transcurrir por carriles bastante alejados de los ideales democráticos originales. La disminución significativa de la participación política de los ciudadanos, el debilitamiento de los partidos políticos en provecho de los liderazgos personalizados y la relegación y sustitución de la promesa política como motivación de las preferencias políticas por la imagen mediática de los candidatos, son actualmente tendencias universales en las sociedades democráticas. Su significación incluso, es materia de debate porque coexisten indicios de despolitización con otros de involucramiento más libre sino más participativo. ${ }^{(2)}$

En Argentina, sobre ese fondo parece dibujarse la posibilidad que se constituya un sistema hegemónico en condiciones tales que hagan posible su perpetuación. Esa posibilidad hegemónica se deriva de la experiencia reciente de delegación política y decisionismo que se afirmó con la emergencia económica iniciada en 1989 y se convalidó con el pacto de Olivos que manufacturó la reforma constitucional de 1994. El poder concentrado, con pocos controles y contrapesos y reacio a argumentar sus decisiones ante la opinión pública fue a lo largo de las mencionadas experiencias consentido por la mayoria de los ciudadanos e incluso considerado como una forma apropiada de gobernar en circunstancias excepcionales. ${ }^{(3)}$

La reforma de la Constitución parece haber confirmado y ampliado las capacidades presidenciales y creado la posibilidad para que un lider prolongue de por vida su reinado sobre la actividad política.

De modo que la hegemonía resultante de la debilidad de contrapoderes y controles y de la inhibición de la censura electoral en razón de los imperativos de la emergencia se potencian con la perspectiva de una permanencia presidencial prolongada en el poder. ${ }^{(4)}$

La propensión al liderazgo ilimitado tiene profundas raíces en la tradición política populista que fuera dominante en Argentina. Esta tradición ha afirmado una imagen de la voluntad popular como una fuerza dotada de unidad y ajena $e$ incluso hostil a la deliberación, que así concebida se oponía a la de la ciudadanía en ejercicio de la libertad política. En verdad, la voluntad popular podía ser el sustento del poder efectivo de un jefe con vocación a encarnarla más que a representarla y por lo tanto que no reconocía ningún principio superior ni límite. Esta concepción de la voluntad popular como si ésta existiese previamente a la constitución de un orden político, la exaltación de la unidad del pueblo como si se tratase de un dato natural derivado de intereses o de una identidad y no una construcción inacabada y perecedera resultado de un proyecto político exitoso, ha posibilitado que la invocación del fundamento democrático, la voluntad del pueblo, fuese el recurso de poderes autoritarios personalistas.

Esta tradición pone en cuestión permanentemente las formas políticas: la ley, la representación política, el pluralismo institucional. La rehabilitación reciente de la doctrina según la cual la Corte Suprema tiene que adaptarse al curso político del 
gobierno y subordinar las interpretaciones constitucionales a ese condicionamiento que fue paralela al cambio en su composición, la presión sobre el parlamento para que se subordine a los deseos presidenciales priorizando la legimitidad del ejecutivo, la idea que la reforma de la Constitución podía ser obtenida por la voluntad de un sector político con el apoyo de una mayoría simple de los ciudadanos obtenida por vía plebiscitaria y la efectivización de esa reforma por un acuerdo entre líderes políticos que fue llevado en su letra al Congreso y por vía de éste a la propia Asamblea Constituyente, son expresiones de la continuidad de principios populistas en la vida política. Por supuesto, éstos están atenuados y no puede ignorarse que los partidos políticos, a diferencia de los movimientos populistas del pasado, no pueden invocar identidades substanciales con el pueblo que no sean emergentes o convalidadas por actos electorales. Pero, se ha heredado de esa tradición una propensión a alinear al pueblo tras los hechos consumados y a designar al pueblo como el soporte de las decisiones personalistas.

Es decir, que las tendencias democrático-liberales efectivamente existentes en la sociedad, algunas de raices más lejanas y profundas y otras más recientes e incipientes, coexisten con otras que orientan la vida política en una dirección contraria.

Sin embargo, la versión contemporánea del populismo no alienta el clásico peligro de la dictadura de las mayorías contra el que prevenía Madison sino más bien el del poder del Uno. No se trata de la amenaza de una mayoría cohesionada en torno a un interés o de una masa movilizada en torno a un proyecto político, situaciones en las que se suma el poder de arriba y la presión del conformismo social, sino una muy distinta resultante de una sociedad atomizada en la que el poder de uno tal como lo preveía y lo temía A. de Tocqueville parece elevarse por sobre la muchedumbre indiferente. ${ }^{(5)}$

¿Nos hallaremos entonces ante la articulación de los restos de la tradición populista con un espíritu democrático mínimo que confina los individuos al ámbito de la vida privada?

En verdad, la retracción en la participación política que ya se ha mencionado anteriormente debe ser considerada en todas sus implicaciones. En conjunto, la identidad política inmutable tiende a ser sustituida por la adhesión reflexiva y en consecuencia cambiante. De modo que no se trata de un unilineal desinterés en los asuntos públicos sino de un doble movimiento: mayor información y mayor electividad; pero también menor pasión política y menor participación. En estas condiciones, la mantención del involucramiento ciudadano, que es más pasivo que en los inicios del proceso de democratización o en los períodos de esplendor populista, depende de la animación de la vida pública y de las innovaciones que pueda generar la actividad desplegada por las instituciones y los partidos.

La disminución de la participación política a la que estamos aludiendo puede derivar por cierto en un retiro ciudadano de la política, aunque no es forzoso que ello ocurra. Aunque se llegara a ese punto no podría considerarse que hay una 
alteración decisiva del régimen político a menos que simultáneamente se produzcan transformaciones institucionales que anulen el pluralismo y la deliberación. Por lo demás, debe tenerse en cuenta que el sistema representativo ha revestido siempre un carácter mixto: aristocrático y democrático. ${ }^{(6)}$ A diferencia de las formas democráticas de la antigüedad, con el sistema representativo el acceso al poder ha estado reservado a los mejores, puesto que la dinámica electoral propende a la selección según los criterios de excelencia existentes en cada momento histórico. Aunque se accede al poder en base a alguna clase de promesa ella no obliga a quien la formula, lo que refuerza la dimensión aristocrática de la investidura del gobernante. Pero, en cambio, los ciudadanos están en una situación de igualdad entre ellos y ejercen un poder soberano al votar pudiendo emitir una valoración retrospectiva sobre los gobernantes salientes; pueden desbaratar al poder por medio de un voto negativo. ${ }^{(7)}$

Esta dimensión, propiamente democrática, de veto al poder se ha hecho más decisiva en la medida en que ha caído la participación por otros canales. Y, sin embargo, ese último recurso democrático parece haber estado inhibido en Argentina, porque la emergencia económica posterior a las crisis hiperinflacionarias de 1989 y 1991 ha conllevado una restricción significativa a la libertad electiva. Por supuesto, puede pensarse que simplemente los electores valoraron positivamente a quienes han traido la estabilidad. Pero, en verdad, la competencia política se ha estancado en ese punto traumático y las elecciones sucesivas parecen condenadas a reiterar la alternativa entre el premio a quienes sacaron al país de la hiperinflación o el riesgo del caos. La estabilidad no se ha objetivado en adquisición colectiva pese a que los principales protagonistas de la oposición la tienen por tal, su perdurabilidad en cambio aparece asociada a la continuidad de un poder y aun de un ministro de economía. Por supuesto, ha existido materia política (las políticas sociales, la imparcialidad del Estado, la conducta pública de los funcionarios) en torno a la cual se formulan opiniones divididas y respecto a la cual el gobierno probablemente habría sido minoritario si ella hubiese llegado a pesar significativamente en la decisión del voto. Pero, en realidad la materia propiamente política ha quedado latente, no ha predominado en la decisión de voto ni ha logrado concitar la atención en las campañas electorales. Puede considerarse que el voto negativo ha sido poco operante en la medida que ha predominado la emergencia económica y en consecuencia la compulsión a congelar en ese punto la electividad. Como se verá esto se constata en el comportamiento disociado de parte del electorado que vota la continuidad presidencial a la vez que manifiesta sus reticencias o descontento, lo que se expresa incluso electoralmente.

También debe tenerse en cuenta que para que el voto negativo se ejerza hace falta una escena política con antagonismos claros. Estos han estado crecientemente inhibidos puesto que la realidad de la crisis que habilitó la definición de una situación de emergencia con concentración de poder, tuvo como correlato la relación poco conflictiva entre un partido oficialista que reclama para sus orienta- 
ciones el estatuto de "pensamiento único" y un partido de oposición que, al menos desde el pacto de Olivos, concibió la política bajo el paradigma de la "cooperación".

Se ha evolucionado hacia un consenso que domina la vida política y la restringe. La propia emergencia económica y el borramiento de los clivajes político-ideológicos en el mundo han debilitado las identidades y los antagonismos políticos. La oposición peronismo versus anti-peronismo prevaleció durante varias décadas implicando propuestas de identificación fuertes y asociadas a alternativas que incluso se excluían mutuamente. Desde 1983, los movimientos políticos se fueron transformando en partidos basados en principios de legitimidad más secularizados y reconociendo reglas comunes de competencia. Pero, si por una parte, radicalismo y peronismo han avanzado en la democratización interna, por otra parte, han visto diluida su identidad distintiva y el antagonismo que caracterizaba su relación.

El consenso ha superado largamente la adhesión a los principios y normas constitutivas del régimen democrático para extenderse a otros ámbitos en particular a la política económica y más aún a justificar la política económica - en tanto dominio reservado de los expertos- como el tema decisivo de la vida pública.

La experiencia de la hiperinflación tuvo un efecto profundamente despolitizador porque a la vez que creó una conciencia sobre la necesidad de consolidar el suelo común de la convivencia secundarizó, como hemos visto, la atención sobre las dimensiones electivas. Esa prioridad de la economía es el núcleo del consenso argentino, que parece alcanzar por mención u omisión otros aspectos de la vida pública.

Este consenso blando, de límites difusos pero que van más allá de lo requerido por la lealtad al régimen político, es un obstáculo significativo a la expansión de la vida política. No es sorprendente que se acentúe la propensión a la representación personalista: que la personalidad de los líderes parezca más significativa que las propuestas que ellos formulan y que los propios líderes aparezcan más como depositarios de atributos personales que como exponentes de proyectos.

De modo que puede discernirse una tendencia al languidecimiento de la vida pública que favorece la conformación de un poder hegemónico; y esta tendencia puede acentuarse aun cuando persista la competencia política periférica la que no tiene por objeto el control del poder sino la participación en él.

Pueden, por cierto, detectarse otras potencialidades en los desarrollos recientes. Existe un pluralismo de la opinión pública fomentado por una dinámica de los medios de comunicación, relativamente independiente de las fuerzas políticas. La escena pública ha incidido significativamente sobre las decisiones del poder.

Pero esta expresión de la opinión tiene un carácter puntual y puede ser finalmente absorbida en sucesivos re-equilibrios del sistema por lo que no sería incompatible con la prolongación de un poder hegemónico que iría introduciendo minirreformas que le aseguren la renovación de su legitimidad. 
De modo que por más significativa que sea la deliberación pública ella sería políticamente inconducente sin las condiciones más permanentes que alimentan la vida política: la competencia partidaria que permitiría vislumbrar la potencialidad de un cambio en el poder, $y$ la división de poderes, $y$ en particular la existencia de un poder judicial suficientemente consistente como para efectivizar un límite al poder político.

Respecto a este último aspecto, probablemente la posibilidad más significativa de limitar el "hiperpresidencialismo" no provenga esencialmente de las atribuciones parlamentarias, que se hallan restringidas tanto por las disposiciones constitucionales como por la complejidad de la función gubernamental y por los requerimientos de eficacia, sino del contrapeso constituido por el poder judicial. Esto no significa que "el gobierno de la ley" pueda ser una alternativa a la voluntad política, pero la vigencia de la ley atempera la concentración del poder, alienta el rol parlamentario en la deliberación y estimula la argumentación pública de las demandas y las decisiones cuando hay derechos lesionados o derechos en pugna.

La existencia de un sistema jurídico eficaz tiene la cualidad de darle una significación distinta a la escena pública. Esta puede finalmente acallarse si cunde la sensación de impotencia cuando las denuncias y reclamos de derechos no encuentran los canales jurídicos para prosperar. El hegemonismo del poder ha tenido una de sus manifestaciones características en la ineficiencia con que la justicia ha tratado los casos de presunta corrupción de funcionarios públicos. ${ }^{(8)}$

De modo que, la existencia de una magistratura independiente afirma en la sociedad una autoridad en tensión, e irreductible, con el poder representativo, lo que por sí mismo limita las posibilidades de hegemonía y favorece en cambio la diversidad. Pero, una magistratura independiente es posible a condición de crear un cuerpo separado de los vaivenes de la voluntad popular y que por su modo de constitución y reproducción no aparezca como su emanación.

Pero, aunque ha sido dicho hasta la saciedad se puede repetir porque viene muy al caso, que una dimensión imprescindible del pluralismo es la existencia de una oposición desafiante. La novedad de la evolución reciente es la incipiente superación del bipartidismo por la aparición de una nueva fuerza política, de centro izquierda. Esta fuerza por su carácter a la vez personalista pero portador de reclamos republicanos acarrea signos contradictorios respecto a la dirección en que pueda producirse la renovación política.

Persiste entonces la interrogación sobre la significación y la permanencia de estos cambios en el sistema de opciones políticas, y sobre si incrementan el carácter competitivo del sistema amenguando las posibilidades del poder hegemónico. 


\section{La situación de excepción favorece la prolongación del poder decisionista}

La situación de excepción se reconoce por la suspensión de las leyes y normas que rigen la relación entre las instituciones y de éstas con la gente. La excepción derivada de la emergencia económica que provocó en Argentina la crisis hiperinflacionaria de 1989 consistió en la cesión de capacidades legislativas al poder Ejecutivo y en el reconocimiento de la gente a esta concentración del poder. La excepción, sin embargo, se prolongó más allá de la urgencia provocada por el desequilibrio monetario y de las reformas del Estado y de la economia que le sucedieron.

El reconocimiento de la situación de excepción se expresa en el aplanamiento que apareja en la relaciones sociales cuya vida normal aparece también suspendida: se pliegan los intereses y se acallan los conflictos sociales. El poder puede decidir con pocos condicionamientos y sin resistencias.

Esta resignación de las identidades conflictivas que son constitutivas de la sociedad se produce en provecho de una lógica de la supervivencia que refuerza el lazo común de pertenencia por sobre los principios de división. El establecer un orden aparece como el interés común que relega el posicionamiento de cada sector y de cada uno en él. Este debilitamiento de los intereses inmediatos facilita el emprendimiento de transformaciones que en situaciones ordinarias son de dificilo imposible trámite.

De este modo, la situación de excepción genera una experiencia que asocia la producción de un orden y la eficacia en la gestión, a la suspensión de la deliberación y al desplazamiento de la representación en favor de la delegación. (9)

Esta delegación es compleja. La situación de excepción implica confiar en quien está en el poder o lo alcanza, haciendo de la capacidad de gobernar un valor independiente del rumbo político y aun de otros aspectos del estilo político. Pero, en la situación de excepción que se creó en 1989-91 no sólo se suspende la deliberación institucional y social en favor de un poder concentrado sino que éste emplea su capacidad de decisión para confiar en un saber. La tentación de considerar la buena política como una techné es permanente pero en la situación de excepción esa propensión puede llevarse aparentemente a cabo. El técnico se puede prevaler de una neutralidad puesto que su acción estaría fundada en el saber y no en la voluntad, lo que refuerza la legitimidad de excepción. Pero, en verdad, los técnicos permanecen como auxiliares de los gobernantes depositarios de la legitimidad. Ello es así porque la política como techné no ha prevalecido completamente. Todavia representar deriva de la capacidad de configurar una imagen en la cual los ciudadanos se reconozcan, es algo construido y no meramente el reconocimiento automático ante la capacidad para administrar. Cada vez más están en juego las relaciones de confianza en imágenes personales, pero ellas sintetizan representaciones de la realidad más vastas que las contenidas en el reconocimiento de capacidades técnicas. Y ello sigue siendo cierto en la situación de excepción. 
La experiencia de la delegación deja trazas institucionales permanentes. Las formas políticas desarrolladas en la situación de excepción tienden a devenir permanentes porque desde el punto de vista de la eficacia, que es la lógica dominante, parecen superiores.

También puede percibirse un reordenamiento de los intereses. Las transformaciones que se generan en la situación de excepción crean una base de apoyo al nuevo orden. Los sectores sociales que se reconvierten, aunque no hayan mejorado sus ingresos, son propensos a adherir a la experiencia de la que son parte. Ello ha sucedido con la ampliación de la lógica de mercado que ha creado nuevas situaciones laborales, empresarias y de consumo. En cambio, los sectores excluidos de antes o de reciente data, si el nuevo ordenamiento se revela eficaz, permanecen relegados y buscan ser incluidos en redes de protección, es decir tienden a considerar su condición social como permanente y no traducible en demanda política. ${ }^{(10)}$

Pero, Carlos Menem ha logrado durante años generar un sentimiento de confiabilidad que excede las consecuencias de las medidas adoptadas en la emergencia y que no reduce su alcance a la sumatoria de sus beneficiarios directos. Existe un amplio espectro de beneficiarios indirectos que consideran un bien simplemente el haber establecido un orden. El gobierno que piloteó la crisis ha transmitido precisamente la sensación de gobernar y satisfizo el requerimiento de autoridad que se reveló en la crisis. (11)

La concentración del poder, sin embargo, desemboca en un sistema bicéfalo. Aunque el depositario de la legitimidad popular es el Presidente, la plenitud de esa legitimidad se asocia a la dupla Menem-Cavallo. Ello es asi no sólo porque el Ministro de Economia cuenta con la confianza del establishment económico nacional e internacional, condición necesaria para la política en curso, sino porque esta figura ha sido el contrapeso y el complemento de la figura presidencial en la legitimidad popular también. Cavallo encarna un saber y cierta distancia respecto a los intereses que se derivan de él. (12)

El sistema personalista tiene otros límites, puestos por cierto nivel de resistencia institucional. Aunque la concentración de poder ha sido grande y se ha incrementado a lo largo del tiempo sin que la reforma de la Constitución haya atenuado esta circunstancia, las instituciones y en particular el parlamento no pueden considerarse como completamente regimentado. ${ }^{(13)}$

En cuanto a la ciudadanía, su apoyo mayoritario al poder que procura perpetuarse prolongando la legitimidad de la situación de excepción no ha estado desprovisto de ambigūedad y su posibilidad de perdurar ha dependido en buena medida de las capacidades limitadas de las oposiciones para cuestionarlo. ${ }^{(14)} \mathrm{El}$ consenso tiene un componente negativo revelador de la vulnerabilidad del mismo. Se trata de una población aliviada por la estabilidad económica, aunque las condiciones de vida sólo hayan mejorado para algunos, y sensible al argumento de la "emergencia" o "excepcionalidad" porque teme que cualquier cambio retrotraiga la situación al periodo hiperinflacionario. Pero, al mismo tiempo, tanto en los 
sectores más populares como en los sectores urbanos independientes que apoyaron la política económica en vigor, se vislumbra una tensión con la figura presidencial. ${ }^{(15)}$

La situación de excepción no cesa necesariamente al aventarse la emergencia que inspiró su declaración. El liderazgo sobre nuevas bases que construyó el presidente Menem desde el poder aspiraba a prolongarse. La legitimidad del poder está basada en el éxito ante el desafio de la emergencia y gracias a él ha podido sobrellevar el incumplimiento de las promesas iniciales. Pero, este decisionismo siendo prisionero de la forma democrática, requiere de la manifestación de la voluntad popular para poder afirmarse. La legitimidad construida sobre estas bases tiende a enfatizar el aspecto ratificatorio de decisiones ya adoptadas en la expresión de la voluntad popular, al punto de atribuirle a ésta una función plebiscitaria.

Esa relación simple se fue reafirmando en los años sucesivos a la declaración de la excepción suprimiéndose mediaciones y controles que "trabaran" o "retardaran" la ejecución de las decisiones políticas. (16)

El obstáculo más difícil de sobrellevar para consolidar el poder hegemónico era el límite de permanencia en el poder establecido por la Constitución nacional. $\mathrm{Y}$ en torno a la pretensión presidencial de obtener la reforma de la cláusula inhibitoria se tensaron lógicas opuestas de legitimidad del orden político.

El argumento con el que el Ejecutivo impulsó la necesidad de la reforma iba a lo esencial, sosteniendo que si el presidente en ejercicio no podía presentarse a la reelección se hallaría proscripto. De modo que debía adecuarse la Constitución al pretendido reclamo democrático de igual comparecencia ante la voluntad popular. Aunque lo que se pretendía era la posibilidad de un segundo mandato, el principio invocado no daba base firme a ningún límite de permanencia en el poder supremo.

Reformar el artículo no reeleccionista requería previamente afrontar otra restricción puesto que la necesidad de la reforma sólo podía emprenderse legalmente con el voto afirmativo de los dos tercios de los diputados y senadores. ${ }^{(17)}$ Esta disposición constitucional está impregnada del espíritu según el cual la Constitución es el objeto de un acuerdo amplio y que cualquier reforma debía ser emprendida sobre la misma base; es decir que excluía la simple expresión de la voluntad popular mayoritaria. Sin embargo, la dinámica que llevó a la reforma de la Constitución se desplegó hasta amenazar con el recurso al voto popular, y el principal partido de oposición fue incapaz de resistir a la misma. (18)

El pacto de Olivos entre Menem y Alfonsín en nombre de justicialistas y radicales, fue forzado por la amenaza de avanzar en la reforma invocando la voluntad popular en detrimento de las formas institucionales. Al firmar ese pacto el jefe del radicalismo produjo un giro completo en su posición que, hasta ese entonces, había sido de acérrima crítica al autoritarismo del gobierno.(19)

Ese pacto inició un encadenamiento de actos que reforzaron el personalismo político y continuaron la invocación de la voluntad popular o su representación contra los procedimientos institucionales establecidos. El pacto fue sellado por un 
acuerdo de jefes, que luego llevaron su decisión a las instancias partidarias. Esto fue particularmente notorio en el caso del radicalismo que fue colocado repentinamente ante una rectificación de rumbo. Pero, aún más, el pacto se estableció sobre bases indefinidas puesto que, invocando el precedente del acuerdo entre Alfonsín y Cafiero de $1988,{ }^{(20)}$ libraba en verdad la reforma a lo que elaboraran los expertos designados por los jefes. La convención partidaria debió avalar el compromiso de Alfonsín que dejaba al partido con una capacidad de maniobra muy restringida y que derivaba la sustancia del acuerdo a lo que surgiera de negociaciones pendientes. $(21)$

De modo que las reformas no fueron discutidas ampliamente por los partidos políticos. Tampoco el Congreso discutió las reformas principales que se encaraban puesto que éste "adoptó" literalmente el texto acordado por los expertos y lo incluyó en el articulado de la ley de necesidad de reforma. Esa ley obligaba a votar por sí o por no, sin posibilidad de tratamiento desagregado, un conjunto de artículos que incluian el que habilitaba la reelección y una serie de reformas supuestamente destinadas a atenuar el presidencialismo, asegurar la autonomía de la justicia y obtener ciertas gratificaciones para la oposición, que el radicalismo había propuesto a cambio.

Aunque la Asamblea Constituyente sí deliberó sobre los puntos no incluidos en la cláusula cerrojo, la adopción de la reforma fue una experiencia que involucró a la oposición radical en un acuerdo para transformar en meramente formales los diferentes momentos institucionales reduciendo la deliberación al mínimo.

El efecto mayor de esta experiencia parece haber sido la de debilitar la oposición, habiéndose integrado una parte del radicalismo al estilo político del partido dominante y apartándose en disidencia otro sector del mismo. Pero, este último y una nueva fuerza política emergente que canalizó en parte el descontento de los sectores opositores de la ciudadanía, no alcanzaron a ser suficientes para frenar los progresos de la estrategia hegemónica. (22)

\section{La reforma de la Constitución}

La reforma de la Constitución fue precipitada por el deseo presidencial de prolongar su mandato, pero esa posibilidad estaba planteada desde el momento en que, en los años 80, se había convocado al Consejo de Consolidación de la Democracia el que había producido ciertos dictámenes que propiciaban como principal cambio la introducción de un sistema "mixto" de gobierno. Esta propuesta estaba en contradicción con las posiciones de los justicialistas favorables a la mantención del presidencialismo puro.

Puesto que el interés de C. Menem era modificar el artículo referido a la reelección, estaba dispuesto a conceder ciertos reclamos del radicalismo poniendo a salvo la intangibilidad del poder presidencial. Diferentes objetivos llevaron a 
ambas partes a la mesa de negociaciones, pero sólo el justicialismo obtuvo lo esencial de lo que buscaba. En cuanto al radicalismo cuya pretensión proclamada era una atenuación del presidencialismo que desconcentrara el poder $\mathrm{y}$ a la vez hiciera menos frágil al régimen político, no parece haber alcanzado su propósito al menos inmediatamente. Lo que sí obtuvo, en cambio, fue cierto rol institucional para la oposición a través del tercer Senador por distrito y la presidencia de la Auditoría General de la Nación.

En cuanto a las consecuencias de la reforma para el régimen político, hay una variedad de aspectos que se presentan a la evaluación y otros que quedan pendientes pues deben ser completados por leyes parlamentarias.

Las consecuencias de la reforma para el presidencialismo vigente no parecen significativas. La figura del jefe de gabinete carece de entidad suficiente como para considerar que el carácter unipersonal del ejecutivo haya sido afectado. La introducción de los decretos de necesidad y urgencia y la delegación legislativa como capacidades del ejecutivo abren las puertas al poder discrecional del Presidente amparado en la imprecisa justificación de "circunstancias excepcionales". El control parlamentario en esta área no está bien definido; los decretos de necesidad serán sometidos a una Comisión Bicameral en el plazo de diez días posteriores a haber sido emitidos, pero el alcance y las consecuencias de esta intervención del Congreso no están aún estipuladas y se establecerán por ley.

Finalmente, la intención de asegurar la independencia del poder judicial a través de un procedimiento innovador para la designación de jueces ha desembocado en un dispositivo de tres momentos que puede favorecer la injerencia partidaria y el predominio del Ejecutivo en las designaciones, tanto más cuanto que la selección inicial presuntamente más profesional efectuada por el Consejo de la Magistratura se vería desnaturalizada al fijarse su composición por ley. ${ }^{(23)}$

En lo inmediato el conjunto de estos cambios no afectan la estrategia hegemónica presidencial, sino que más bien parecen institucionalizarla. Esta interpretación se ve reforzada por la forma que adoptó definitivamente el artículo 90 referido a la reelección presidencial: "El presidente y el vicepresidente duran en sus funciones el término de cuatro años y podrán ser reelegidos o sucederse recíprocamente por un sólo periodo consecutivo. Si han sido reelectos o se han sucedido recíprocamente no podrán ser elegidos para ninguno de ambos cargos, sino con el intervalo de un período". En la redacción de este último párrafo, el justicialismo logró alterar el enunciado explícito del pacto de Olivos y lo estipulado en la ley de necesidad de la reforma. ${ }^{(24)}$

De este modo, por una modificación subrepticia de lo pactado, una persona podrá hacerse elegir dos veces consecutivas alcanzando ocho años continuos y luego de un intervalo de cuatro años podría reanudar el ejercicio de la función presidencial y así sucesivamente. Es decir, podría controlar de por vida el poder político si lograra mantenerse en la dirección de una fuerza política hegemónica en los intervalos entre los mandatos de ejercicio de la presidencia. El conjunto de 
la reforma efectuada, al menos en cuanto a sus consecuencias inmediatas, parece inspirada por el espíritu que se deriva de esta cláusula.

La limitación de los mandatos es un principio generalizado en los regímenes políticos, particularmente en los presidencialistas, como modo de preservar cierta igualdad política. ${ }^{(25)} \mathrm{El}$ control prolongado del poder asegura un acceso privilegiado a recursos políticos y forma un bloque de beneficiarios e interesados en la continuidad de los gobernantes, $\mathrm{e}$ incluso traba la competencia política en el seno del partido dominante. En estas circunstancias, el poder tiende a encarnarse más aún en una persona y la democracia deviene en consecuencia cada vez más restringida porque la renovación en el poder ejecutivo es cada vez menos posible. El límite temporal al ejercicio del poder es una protección contra la cristalización de una desigualdad política que a su vez crea propensión a la arbitrariedad del poder. Ciertamente la igualdad política aun en plena democracia es relativa, puesto que en este ámbito existen desigualdades constitutivas como existen en el de la economía o la cultura, pero aun siendo relativa la igualdad política es esencial para la democracia.

Sin embargo, no todas las reformas efectuadas pueden ser subsumidas en un mismo juicio crítico. Y la significación de algunas de ellas debe ser apreciada en la perspectiva de los cambios que se están produciendo en las sociedades democráticas. La concentración del poder, que es el rasgo más discutible del sistema institucional tal como se perfila no puede ser simplemente explicado por la vocación hegemonista del actual poder, aunque éste le da una inflexión particular. La ampliación de las potestades del ejecutivo responde a una tendencia que se verifica en otras sociedades democráticas y que ha sido justificada en nuestro país. (26)

El problema que plantea la reforma efectuada, considerado desde esta perspectiva, es más bien el de la indefinición en las atribuciones excepcionales del Ejecutivo y el de su control. Ello podría acarrear, al ser emitidas las leyes complementarias, un rol marginal para el Congreso favoreciendo un uso inmoderado de esas prerrogativas por parte del Ejecutivo.

Desde el punto de vista institucional lo que parece más inquietante aún es la incerteza sobre la evolución del poder judicial. La existencia de un cuerpo independiente abocado a la custodia de la Constitución y a la aplicación de la ley es problemático en todas las sociedades democráticas, puesto que este cuerpo se integra a partir de decisiones de otros poderes. Lo que parece afirmar mejor su existencia es la primacía, en su integración y reproducción, de criterios corporativos, es decir, la autorreproducción de los jueces. Esta alternativa encierra peligros de autonomización aristocrática, pero parece la más conveniente en el caso de países poco propensos al respeto de las formas en razón de sus tradiciones.

La otra salvaguardia ante la concentración del poder es la expansión del espacio público deliberativo. El rol de los medios de comunicación ha sido decisivo en ampliar la información y en llevar la luz pública a lugares presuntamente públicos pero anteriormente protegidos por el secreto o la intimidad. ${ }^{(27)}$ Algunas 
de las nuevas disposiciones constitucionales alientan la deliberación al obligar o incitar a los funcionarios a la producción de informes y a la realización de controles. (28)

Vista en conjunto la reforma de la Constitución evidencia también la huella de los intereses circunstanciales que estaban en juego. Muchas de las disposiciones institucionales tienen la hibridez característica de materias en las que ha habido concesiones mutuas aunque no equivalentes. El caso más característico es el del jefe del gabinete de ministros. Pero, también es visible en el peculiar sistema de ballotage adoptado para las elecciones presidenciales que fija un umbral del $45 \%$ de los votos válidos y en algunas circunstancias un porcentaje inferior para consagrar desde la primera vuelta un ganador. ${ }^{(29)}$

Idealmente la característica central del sistema de doble vuelta es que el elector vota dos veces, con información e intenciones diferentes cada vez. Ello supone que en la primera vuelta se fomenta la diversidad de candidaturas porque hay una disponibilidad del electorado para emitir un voto "libre" de restricciones de cálculo. La segunda vuelta comporta un voto con conocimiento puesto que ya se han expuesto las posibilidades de cada uno de los candidatos. Esta segunda vez, interviene tanto una elección positiva como una negativa. ${ }^{(30)}$ Pero, tal como el procedimiento ha sido concebido en Argentina no se posibilita una plena libertad en la primera vuelta. El sistema adoptado es un híbrido dificil de descifrar pero que resulta de una tensión entre un partido hegemónico, que piensa en cómo ganar en solitario, y que en consecuencia debe crearse las mejores condiciones para lograrlo en la primera vuelta, y un partido minoritario pero con la esperanza de provocar una segunda vuelta en la que sea la expresión de una coalición implícita que pueda ganar. Lo que es dificil identificar en el sistema establecido es un principio objetivo desligado de los intereses de coyuntura. ${ }^{(31)}$

Pero, la Constitución no está concluida puesto que en la Convención Constituyente se inició un proceso de reformas que debe ser continuado con las leyes que debe sancionar el Congreso para complementar varios artículos. Esta participación parlamentaria en su elaboración le da a la Constitución un carácter al menos parcialmente flexible y crea la posibilidad de un proceso de reforma permanente. ${ }^{(32)}$ Este proceso de reforma se inscribe en un espíritu diferente que el contemplado inicialmente en la Constitución no sólo porque de hecho habilita capacidad constituyente al Congreso, sino porque la mayoría requerida para esas leyes es absoluta y no de dos tercios como para la reforma ordinaria. (33)

El radicalismo al dejar inconclusas las cláusulas en las que no pudo llegar a un acuerdo con el justicialismo confiaba en continuar las negociaciones en el Congreso, subestimando la posibilidad que el oficialismo contara con mayoría propia como en verdad sucede desde la renovación de las Cámaras producida en 1995. (34) Como este pronóstico fue erróneo las leyes complementarias están ahora libradas al arbitrio de la mayoría justicialista. De modo que el giro que tome la continuación de la reforma dependerá de la evolución de eventuales planes reeleccionistas del 
actual mandatario, o de su relación con su eventual sucesor, y de la medida en que los legisladores oficialistas hagan prevalecer sus intereses de cuerpo u opiniones o se plieguen a una estrategia hegemónica comandada desde el ejecutivo. En todo caso, la flexibilización constitucional favorece las posibilidades de consolidación de un poder hegemónico y crea una base inestable para la vida política. ${ }^{(35)}$

Se ha especulado sobre la posibilidad que en el largo plazo las instituciones consagradas por la Constitución reformada contribuyan a la profundización de la democracia y a su estabilidad. Por supuesto, hay aspectos de la reforma que aquí no se han considerado y que revisten un progreso en ese sentido, como las convenciones internacionales de derechos humanos, el defensor del pueblo, la consulta popular y muchas otras innovaciones. Pero, el futuro del régimen político está cifrado en la organización de los poderes principales, y en particular del gobierno. Aun en este ámbito hay innovaciones positivas como la autonomización de la ciudad de Buenos Aires cuyas autoridades no serán más designadas por el Presidente. Es posible que en el futuro también ciertas formas de control sobre los actos administrativos se mejoren. Pero, la idea que se ha atenuado el presidencialismo y en particular que el jefe de gabinete podría ser una pieza de negociación en caso de un Presidente que no contara con mayoría propia es infundada puesto que las limitadas atribuciones de ese cargo parecen excluir la figura de una cohabitación a la francesa. ${ }^{(36)}$

El futuro de la democracia estará sin duda condicionado por la experiencia de la reforma y por el contenido de la misma, pero hay otro aspecto de la vida pública, la escena de las fuerzas políticas, que pesará también y con cierta independencia de las formas constitucionales, en la modelación de ese futuro.

\section{¿Crisis del bipartidismo?}

En las elecciones para convencionales constituyentes de 1994 y más nítidamente en la elecciones generales de 1995 se esbozó una fractura del bipartidismo tradicional en la política argentina. Por el momento, este pluripartidismo es aún más un dato electoral que una realidad institucional, puesto que la tercera fuerza emergente cuenta con una representación parlamentaria relativamente reducida y no tiene un control significativo de poderes locales. ${ }^{(37)}$

Sin embargo, esta novedad parece provocar cambios significativos en la escena política y particularmente en el campo de la oposición política. La fuerza emergente nacida propiamente en el espacio público y conformada en torno a un liderazgo personalista, sin soporte en un movimiento social como fue el caso de las otras fuerzas políticas principales en sus orígenes, se formó y expandió con una crítica política al poder referido a su concentración, al estilo presidencial y a la corrupción. (38) Por sus orígenes se desinscribe del antagonismo clásico entre peronismo y antiperonismo lo que le permite aspirar a un posicionamiento que busca redefinir 
los alineamientos electorales compitiendo en ambas direcciones. Por una parte, pretende constituir una oposición más intransigente y ajena a las prácticas cooperativas en que se había involucrado el radicalismo desde el pacto de Olivos. Pero, por otra parte, se considera apta para absorber desprendimientos de ambos partidos tradicionales.

El radicalismo, en crisis desde el pacto de Olivos, se vio aun más cuestionado al ser relegado a un tercer puesto en las elecciones nacionales de 1995. Sin embargo, permanece atravesado por el dilema entre la oposición cooperativa - que toma al pacto de Olivos como el inicio de una asociación subordinada con el poder con aspiraciones a ocupar ciertos lugares institucionales e incidir en la perspectiva de un cambio de política económica-y la oposición confrontativa.

El cambio que se insinuó en la escena política afectó también al justicialismo. Esta fuerza, favorecida por la debilidad de la oposición tradicional, ha tendido a que sus conflictos internos ocupen toda la escena política. La puja entre los dos referentes principales del gobierno, a lo que se suma las tensiones con otros precandidatos que se perfilan para las elecciones presidenciales del 99 configuran un panorama en que las eventuales rotaciones en el poder parecen estar contenidas en el oficialismo. Pero, los perdedores de estos enfrentamientos dificilmente podían concebir un futuro político fuera del justicialismo. Ahora, la emergencia de una tercera fuerza que no es el antagonista histórico y que puede pretender a una mayor continuidad con los postulados de justicia social, aunque sea más crítica del poder parece más apta para fomentar alianzas o cooptaciones. ${ }^{(39)}$

Todas las identidades políticas se hallan afectadas por la mencionada evolución de la escena política. Esta mayor interrelación existente entre ellas se debe al debilitamiento de las identidades más cerradas del pasado. Sin embargo, se podía suponer que la evolución de los tradicionales movimientos políticos (el más característico de los cuales era el peronismo, aunque el radicalismo participaba también de rasgos movimientistas) a partidos les daría una identidad más definida en torno a una referencia programática. Pero, no ha sido así, los partidos son menos autocentrados, menos caracterizados por un espíritu "interno" y más dependientes de la sociedad a la que procuran expresar. Sin embargo, como la sociedad no está estructurada en clases o corporaciones consolidadas como lo estaba en el pasado sino cada vez más atravesada por movimientos de opinión poco articulados entre sí, la determinación social es débil y en ese sentido las fuerzas políticas son más libres, están menos sujetas a un mandato de la sociedad, o al menos a categorías o grupos a los que pretendian expresar en el pasado. En este sentido los partidos son potencialmente más libres al formular sus propuestas políticas, aunque sometidos en permanencia a la puesta a prueba de su conexión con la sociedad.

Esta nueva tendencia en la representación ha modificado la naturaleza de la lucha política. En el pasado la política expresó conflictos que parecían derivados de la lucha social. El clivaje peronismo-antiperonismo tenía sin duda componentes propiamente políticos relativos a los derechos políticos y a la organización de la 
vida pública, pero el primero de los términos, que fue durante años el elemento activo de la polarización, se afirmaba como la expresión de los trabajadores e impregnaba fuertemente el antagonismo de una significación social.

Actualmente, la constitución de dos campos enfrentados se deriva directamente de la distinción entre quienes controlan el poder y quienes pretenden sucederles y formulan sus propuestas a partir de la crítica inmediata del poder. Ello es así porque la lucha política no sólo no expresa más realidades sociales fuertes sino que no se plantea más como alternativa entre órdenes políticos distintos; por cierto las diferencias en las concepciones de la democracia son considerables, pero remiten más a prácticas silenciosas y a la invocación de situaciones de excepción que a doctrinas contrapuestas. Los antagonismos políticos son dificiles de constituir porque existe un "consenso blando" - ya mencionado anteriormente- que traba la formulación de alternativas nítidas. Es decir, que las fuerzas políticas tienden a extender sus acuerdos, generalmente implícitos, a los grandes problemas y en especial a la política económica como si las decisiones en ellos fueran más dependientes de la justeza de criterios técnicos que de la inspiración de la voluntad política. Un consenso demasiado amplio, pero que curiosamente se revela poco consistente en lo que debería ser su terreno propio: la observancia de la ley y la preservación de las instituciones.

De modo que la oposición política propone, si logra constituirse, una alternativa de reformas. Su dilema es cómo lograr un equilibrio entre la afirmación de una diferencia que justifique la aventura política de un cambio en el poder, y el reconocimiento básico del consenso pos-hiperinflacionario sin lo cual se colocaría fuera del umbral mínimo de participación en los valores comunes lo que le haría perder toda credibilidad.

La posibilidad que el justicialismo conserve un poder hegemónico durable se sitúa en este contexto. En esa posibilidad se conjugan la situación de poder legitimado por haber afrontado exitosamente la emergencia económica y la preservación de una base social heredada de un pasado más lejano.

El poder tiene a su favor el expresar un orden $y$, a menos que una crisis cuestione esa posición, toda oposición se halla ante el desafio de mostrar capacidades mayores de gobierno. A la vez, toda oposición será impugnada precisamente en su carácter de tal, es decir por carecer de la experiencia valedera en la gestión de los asuntos públicos. La minusvalía de la oposición se retroalimenta en la medida que se prolonga una legitimidad "economicista". ¿Quién mejor que quienes sacaron al país de la hiperinflación para prevenir una eventual recaída, cuyo posibilidad aparece afirmada por cimbronazos recurrentes? Sin que sea posible, como lo fue en el período 1989-91, enunciar una situación de excepción, la fragilidad del equilibrio logrado puede justificar la invocación de una legitimidad economicista por largo tiempo.

Por supuesto, la gestión de excepción crea descontento y abre la posibilidad de concebir y prometer otro modo de gobernar, pero ello supone la ruptura con 
algunos de los enunciados del consenso blando. Pero, si ello no sucede, la oposición puede quedar reducida a ser una Casandra que anuncia y espera que una crisis de la economía le devuelva las esperanzas de un recambio en el poder.

Los recursos del poder van más allá de la credibilidad provista por el éxito en la emergencia. En una época en que - como se ha visto- los partidos políticos se hallan en crisis, el oficialismo dispone del propio dispositivo estatal que se superpone a la red partidaria. Esta materialidad del poder político se prolonga con el consenso proveniente del establishment económico nacional e internacional que brinda un refuerzo de legitimidad, pues afirma la idea que los asuntos públicos tienen su alma en el mundo de los negocios y que sólo esta política económica y con estos dirigentes son viables.

De modo que en un mundo en que se está diluyendo el vínculo que pareció existir en el pasado entre relaciones socio-económicas y vida política, el justicialismo cuenta aún con bases sociales consistentes. Las que tienen que ver con el establishment les dan crédito a la posibilidad de gobernar y a las amenazas catastrofistas asociadas con un cambio de gobierno. Otro polo de consistencia proviene de la identificación de los sectores populares, y de buena parte de los excluidos, con el peronismo. Esta adhesión al oficialismo ha soportado los avatares de la política económica y en verdad no parece depender enteramente de los mismos. La cautividad electoral de este sector responde a una completa ajenidad a la comunicación política y constituye otro pilar social en la prospectiva de un poder hegemónico durable.

Lo indicado ilustra la debilidad del poder político ante el poder económico y social. O dicho en otros términos, la debilidad de la política ante las diferentes coagulaciones: la de los intereses económicos dominantes asociados a esta orientación económica y a estos gobernantes, la de una parte de la ciudadanía pasiva y aferrada a un orden que considera amenazado, la de sectores populares encapsulados en la sigla que en el pasado les brindara bienestar.

Pero, el poder que emerge de la política, de la capacidad de criticar un orden y concebir otro, es el único recurso del que dispone la oposición. Es un recurso genuino puesto que regularmente el poder político está en juego en elecciones libres y se mantiene la posibilidad de ejercer las libertades públicas.

La posibilidad de generar adhesión ciudadana a través de su prédica es el principal resorte de construcción de poder político para la oposición, puesto que ésta carece de una capacidad significativa de poner en movimiento fuerzas sociales y su capacidad de bloqueo o presión institucional es en este momento reducida.

El dilema de la oposición es encontrar las bases para una alternativa política capaz de contrarrestar la debilidad de recursos a la que nos hemos referido. Una alternativa política para la oposición tiene un gran componente de negatividad puesto que justamente su mordiente es la crítica derivada de la experiencia que todos hacen con el ejercicio del poder existente. Esa crítica tiene que ser suficientemente radicalizada como para permitir vislumbrar su diferencia. Pero, no puede 
llevar a una polaridad extrema que pueda confundirla con el antagonismo peronismo-antiperonismo en el que lo que estaba en juego no eran alternativas en un sistema común sino propuestas de orden político antagónicas. La evolución hacia un poder hegemónico prolongado no puede hacer olvidar el hecho que, sin embargo, se mantienen las premisas esenciales que caracterizan una sociedad democrático-liberal. El funcionamiento de ésta no es pleno, por cierto, pero no puede considerarse que se esté ante un cambio de régimen político en tanto persista el recurso al pronunciamiento popular para instituir al poder representativo y exista un nivel razonable de libertades públicas.

El poder que se pueda organizar políticamente debe competir con la inercia de las tendencias sociales orgánicas que favorecen el statu quo y la repetición. El poder político al que pueden aspirar las actuales oposiciones es, como hemos visto, un poder ciudadano, distante de las identidades sociales y hasta cierto punto de los intereses. Un tal poder es difícil de constituir en condiciones de desmovilización ciudadana y de desinterés por los asuntos públicos, pero la experiencia reciente, la propia emergencia ciudadana de una nueva oposición parecen indicar que no es imposible. Un tal poder puede adquirir consistencia en las áreas de nuestra sociedad involucradas en la información y circulación políticas pero puede operar también como una locomotora que tracciona llevando en su arrastre los sectores más orgánicos del conglomerado social. ${ }^{(40)}$

\section{Notas}

(1) Hasta poco antes de la guerra de Malvinas los partidos políticos principales estuvieron embarcados en conversaciones para una transición cívico militar e ignoraron, salvo excepciones, la denuncia de la 'desaparición de personas'.

(2) Ver B. Manin, Princifpes du gruvernement representalif, Calmann-Levy, 1995.

(3) Para una interpretación del menemismo formulada antes de la reforma de la Constitución ver J. Nun, "Populismo, representación y menemismo", en: Soriedad, N² 5, Buenos Aires, UBA, octubre, 1994.

(4) N. Botana justifica el empleo del término hegemonía para referirse al "ctual poder : "La hegemonía no sólo califica la capacidad de que hace gala un gobernante o un partido para ejercer prolongadamente el poder con supremacía sobre los otros (atributo compartido con los sistemas de partido predominante), sino que también alude, en nuestro último lustro, a la confusión del gobierno con el Estado". N. Botana, "Las transformaciones institucionales en los anos del menemismo", en: Sociedad, N6, Buenos Aires, UBA, abril, 1996. Este último punto, referido a la pérdida de autonomía funcional de la burocracia de Estado que debilita los controles sobre las decisiones gubernamentales, no es generalmente tomado en cuenta. (5) Alexis de Tocqueville describió una nueva clase de despotismo emergente relacionado con el tipo de individualismo que se genera en las sociedades democráticas. Lo hizo en estos términos: "Creo pues, que el tipo de opresión que amenaza a los pueblos democráticos no se parecerá en nada a la que le precedió en el mundo; nuestros contemporáneos no recordarán algo ya sucedido y semejante. Yo mismo busco en vano una expresión que reproduzca y encierre exactamente la idea que me formo; las antiguas palabras 
de despotismo y tiranía no son adecuadas. La cosa es nueva; es preciso entonces tratar de definirla, ya que no puedo nombrarla".

"Si imagino con qué nuevos rasgos podría el despotismo implantarse en el mundo, veo una inmensa multitud de hombres parecidos y sin privilegios que los distingan incesantemente girando en busca de pequeños y vulgares placeres, con los que contentan su alma, pero sin moverse de su sitio. Cada uno de ellos, apartado de los demás, es ajeno al destino de los otros; sus hijos y sus amigos acaban para él con toda la especie humana; por lo que respecta a sus conciudadanos, están a su lado y no los ve: los toca y no los siente; no existe sino en sí mismo y para él sólo, y si bien le queda aún familia, se puede decir que ya no tiene patria".

"Por encima se alza un poder inmenso y tutelar que se encarga exclusivamente de que sean felices y de velar por su suerte. Es absoluto, minucioso, regular, previsor y benigno. Se asemejaria a la autoridad paterna si, como ella, tuviese por objeto preparar a los hombres para la edad viril; pero, por el contrario. no persigue más objeto que fijarlos irrevocablemente en la infancia; ese poder quiere que los ciudadanos gocen, con tal que no piensen sino en gozar. Se esfuerza con gusto en hacerlos felices, pero en esa tarea quiere ser el único agente y el juez exclusivo, provee medios a su seguridad, atiende y resuelve sus necesidades, pone al alcance sus placeres, conduce sus asuntos principales, dirige su industria, regula sus traspasos, divide sus herencias ¿no podria librarles por entero de la molestia de pensar y el derecho de pensar y el trabajo de vivir?"

"De este modo cada dia se hace menos útil y más raro el uso del libre albedrio; el poder circunscribe asi la acción de la voluntad a un espacio cada vez menor, y arrebata a cada ciudadano su propio uso. La igualdad ha preparado a los hombres para todas estas cosas: para sufrirlas y con frecuencia hasta para mirarlas como un beneficio..."

"Siempre he creído que esta clase de servidumbre, reglamentada, benigna y apacible, cuyo cuadro acabo de ofrecer, podría combinarse mejor de lo que se piensa comúnmente con algunas de las formas exteriores de la libertad, y que no le sería imposible establecerse junto a la misma soberanía del pueblo". Estas líneas de La democruria en Aménira son consideradas como proféticas por haber concebido la posibilidad de un poder omnímodo originado en la soberania del pueblo que no encuentra freno debido a la ausencia de una ciudadania constituida. La pérdida de la libertad política sería no obra de una dictadura sino de una evolución aceptada de las costumbres. Por cierto el poder tutelar al que alude Tocqueville hace más pensar en el Estado Keynesiano, que en el Estado mínimo al que aspiran las políticas conservadoras; este último es más indiferente que tutelar. Pero esta salvedad no afecta la fuerza evocativa de las lineas mencionadas.

(6) B. Manin, op. cit.

(7) Sobre la importancia del voto negativo. K. Popper ha señalado: "Lo único que importa es la capacidad de los ciudadanos de destituir el gobierno sin violencia. Existen varios medios, siendo el mejor el voto: elecciones generales o el voto de censura de un parlamento elegido democráticamente. Este es el punto clave. Es la respuesta a la pregunta: ¿cómo podemos organizar el Estado con el fin de impedir al gobierno de hacer demasiado mal?", en: "Sur la théorie de la démocratie", Médiasponuoirs $\mathrm{N}^{2}$ 10, avril-juin, 1988, citado por P. Rosanvallon, en: Ia République du centre, Calmann-Levy, 1988.

(8) Hay quienes consideran que la relevancia que ha adquirido el tema de la corrupción es un signo de despolitización porque se refiere a la moralidad de los funcionarios con independencia de las políticas emprendidas $y$ afecta tanto a la derecha como a la izquierda. En la puja política, la prioridad de la honestidad de los candidatos relegaria las propuestas programáticas. En parte es asi, puesto que la despartidización y el no prebendalismo de los organismos y cargos públicos deberian ser valores republicanos compartidos.

Sin embargo, también, la importancia adjudicada a este tema tiene que ver con una concepción de la lucha política que no opone la sustantividad a las formas. Que los recursos directos o indirectos que están a disposición del poder político sean tratados como un botín suele no ser el resultado de comportamientos individuales sino estar asociado a culturas de grupos que consideran al poder como colocado por sobre la ley, y el éxito en la lucha politica como la fuente de un derecho sobre los bienes comunes. 
La denuncia de la corrupción conlleva una concepción pluralista de las instituciones políticas, es una puja por la ampliación de la democracia en el sentido del reclamo de un ámbito estatal que por el juego de poderes y contrapoderes no puede ser apropiado por nadie.

La vigilancia y eventual crítica del estilo presidencial se sitúa en la misma línea de valores republicanos. Quien representa el poder es una figura en quien la sociedad debe poder reconocerse. La exhibición de los recursos de goce privado que ofrece el poder, desvirtúan la figura presidencial presentándola en su privacidad y particularidad y generando los sentimientos que corresponden a ese tipo de aparición. En el mismo sentido, el desborde de la palabra presidencial hacia temas diversos que los situan como un particular afectan su posibilidad de representar a la sociedad en su unidad.

(9) Sobre este tema se puede consultar el ya clásico texto de G. O'Donnell: “¿Democracia delegativa?”. en: Cuadernos de Clueh, N²61, Montevideo, 1992.

(10) V. Palermo y M. Novaro en Politica y poder en los años de Menem, manuscrito, 1995, al referirse a los pobres en el contexto contemporáneo lo hacen en estos términos:"Pobres que en lugar de demandar por poder y la atención de intereses específicos agregados sectorialmente, hallándose al borde de la marginación, demandaban protección y seguridad". Editado como: Política y poder en el gobierno de Menem, Buenos Aires, FLACSO/Grupo Editorial Norma, 1996.

(11) Como señala Torre: "Vista desde esta perspectiva - como la superación de un impasse de raíz hobbesiana - se comprende que la salida de la crisis hiperinflacionaria sea buscada por medio de un recentramiento de la autonomía del Estado. Esto es, por una intervención que descansa en la aplicación de poderes de excepción (como los decretos de urgencia, las medidas provisorias), en el esfuerzo por despolitizar las decisiones y los conflictos invocando la racionalidad económica, en fin, en un mandato en el cual el ejecutivo presidencial se inviste y se nutre de esa demanda de gobierno a la que ya aludimos y que genera la propia crisis"; J. C. Torre: América latina, el gwhierno de la democracia en tiempos difíciles, Buenos Aires, Instituto Torcuato Di Tella, mayo, 1991.

(12) El desplazamiento de D. Cavallo del Ministerio de Economía no parece alterar la validez de estas afirmaciones.

(13) Indicando la inadecuación que supone considerar el poder existente en términos de democracia delegativa Palermo y Novaro afirman: "En realidad, creemos que se aproxima mucho más a los hechos, un escenario caracterizado por el conflicto entre dos protagonistas, un gobierno que procuró desde el comienzo imponer una modalidad unilateral de gestión política, y configuraciones partidarias y parlamentarias que, desde la oposición o las fuerzas propias, fueron adquiriendo capacidad de limitar la efectividad de los intentos de excluirlos completamente de las decisiones". Agregando más adelante "la imagen que puede entreverse en materia de acceso de la sociedad a las instancias de decisión gubernamental es la siguiente: de un lado, el polo fuerte, un Presidente que se atribuye la potestad de gobernar en nombre del pueblo - y ciertamente ha sido capaz de consolidar un vínculo carismático con parte importante de quienes se identifican con esta apelación-, pero que no 'escucha' demandas provenientes de ese campo, sino que, más bien, confia en su capacidad de determinar cuál es el 'verdadero interés' del mismo y en que éste, al cabo de los resultados de sus decisiones, lo reconocerá renovado en su consentimiento. Y, del otro lado, el polo débil, un Congreso en el que se agolpan las expresiones de organizaciones y grupos sociales que no forman parte del reducido grupo de actores a quienes el Poder Ejecutivo 'escucha'". V. Palermo y M. Novaro, op. cit.

(14) Ver al respecto mi artículo "Hay todavia lugar para la voluntad politica?", en: Coloquio del Isen, 27 al 19 de julio 1995.

(15) En la provincia de Buenos Aires a lo largo de la campaña electoral para las elecciones generales de 1995 se manifestó un hiato entre la intención de voto a Gobernador y a Presidente, en favor de la primera. Esta diferencia que finalmente no resultó tan significativa como anunciaban ciertas encuestas (Menem $51.8 \%$; Duhalde $56.7 \%$ ) era atribuible a la imagen más peronista del candidato a Gobernador de la provincia de Buenos Aires.

En cuanto al voto de los sectores medios urbanos, una buena ilustración es la de la Capital Federal, distrito en que resultó triunfante en 1995 el candidato de la oposición ( $44 \%$ ): sin embargo Menem obtuvo un porcentaje elevado de votos $(41 \%)$, cifra muy superior a la de los candidatos a diputados justicialistas en 
esta elección y a la de los candidatos justicialistas en otras elecciones. Por supuesto aqui caben dos interpretaciones. Una es que la figura presidencial tiene un arrastre muy superior a la de su propio partido porque la adhesión a su política suscita una pluralidad de convergencias. Otra es que, en verdad el voto al candidato justicialista en las elecciones presidenciales es superior porque al voto positivo se suma un voto negativo de quienes expresan su temor al cambio. Es decir, que quienes resisten el estilo Menem pero apoyan su política económica, lo votarian a Presidente para asegurar la continuidad de esa política pero lo harian en boletas electorales de partidos que tienen sus propios candidatos a diputados y concejales expresando así sus recelos y rechazos. En la referida elección la lista oficialista a diputados obtuvo el $23 \%$ de los votos y las otras listas que incluían a Menem como candidato a Presidente junto a sus propios candidatos a diputados obtuvieron en conjunto el $16 \%$ de los votos.

(16) Lo más significativo fue el cambio de composición de la Corte Suprema a través del aumento en el número de sus miembros. Pero también se sustituyó al Procurador general de la Nación, al Tribunal de cuentas, a la Procuración del Tesoro, a la Inspección general de justicia y a la Fiscalia nacional de investigaciones administrativas.

(17) Uno de los temas de polémica cuando el proyecto de reforma llegóal parlamento fue el de interpretar si se trataba de los dos tercios de los legisladores presentes en el recinto o de los legisladores totales.

(18) De hecho, después que el justicialismo triunfara en las elecciones del 3 de octubre de 1993, el gobierno habia convocado una Consulta popular, referida a la reforma de la Constitución para el 21 de noviembre.

(19) El radicalismo conducido por R. Alfonsín encaró desde 1989 la oposición a C. Menem con el esquema de los años ochenta, identificando a su fuerza política como la mejor encarnación de los ideales democráticos y cuestionando al nuevo poder por su presunta propensión autoritaria. Este esquema le impidió comprender los requerimientos de orden provenientes de la sociedad y el aval con que contaba el estilo decisionista. Por cierto, era sumamente dificil para la oposición encontrar su lugar en una situación en que los actos de gobierno ordenadores concitaban un gran consenso. La oposición radical desconoció los éxitos de la política económica pareciendo así retacear su acuerdo a lo que era percibido como un logro para todos. En lo que hace a la reforma de la Constitución su oposición a considerar siquiera una cláusula que permitiera dos mandatos presidenciales consecutivos fue terminante hasta que con el pacto de Olivos se produce un cambio completo de posición.

Todo indicaba que si el plebiscito anunciado hubiese resultado terminantemente favorable para el si a la reforma, el radicalismo se habría desgranado dando los votos faltantes en la Cámara de diputados para alcanzar los dos tercios necesarios para la reforma. De modo que Alfonsín pudo justificar su viraje con el argumento implicito de la incapacidad de frenar la ofensiva gubernamental lo que incluia la posible fractura de su partido, $y$ con el argumento explicito de que al aceptar la posibilidad de la reelección actuaba por el bien común porque aventaba peligros mayores para el país. La contradicción inherente al argumento que para frenar un poder hegemónico se cedia ante él se procuraba superar replicando que se habian obtenido modificaciones progresistas en el régimen político a cambio de la cláusula de la reelección.

(20) En realidad, el 14 de enero de 1988, R. Alfonsín y A. Cafiero emitieron un comunicado de prensa en el que se mencionan vagos objetivos para la reforma de la Constitución. Entre ellos se proponían obtener un consenso "para favorecer mecanismos que establezcan la elección directa del Poder Ejecutivo; protejan a ese órgano del desgaste de las cuestiones políticas cotidianas, desconcentrando funciones que no correspondan estrictamente a la jefatura del Estado; flexibilizando la marcha de la administración según las situaciones políticas o electorales cambiantes; examinen el acortamiento de los mandatos; hagan más estrecha y coordinada la relación entre el Ejecutivo y el Parlamento, permitiendo acuerdos interpartidarios en su seno que faciliten la agilidad y eficiencia de la administración y su contralor por el Congreso..."

(21) La resolución que aprobó la convención radical establecía en su punto primero "Instruir a los legisladores nacionales de la UCR para que voten positivamente el proyecto de ley que declara la necesidad de la reforma de la Constitución sobre la base de las tratativas ya iniciadas y los acuerdos a los que 
finalmente se arribe". El texto completo de esta resolución en R. Alfonsín, Democracia y consenso, Buenos Aires, Corregidor, 1996.

(22) Una valoración diferente del proceso de reforma de la nueva Constitución en: L. de Riz, "Reforma constitucional y consolidación democrática", en: Sociedtud, N 6, Buenos Aires, UBA, abril, 1995.

(23) El procedimiento constitucional establece que el Consejo de la Magistratura somete una terna al Presidente que de ella seleccionará al nominado. Finalmente, el Senado debe dar su acuerdo.

(24) En estos documentos se indicaba sólo: "Reducción del mandato presidencial a cuatro años con reelección inmediata por un solo periodo, considerando al actual mandato presidencial como un primer periodo".

(25) De los países latinoamericanos sólo Nicaragua, Paraguay, Perú y Argentina contemplan la reelección inmediata y la mitad de los restantes la prohiben en absoluto; en G. Sartori, Comparative comstilutional Engineering, New York University Press, 1994.

(26) Asi J. Vanossi sostiene que el sistema parlamentarista "sería el gran aliado para el mantenimiento del statu quo, cuando un país está necesitado de cambio y de transformación, lo cual significa fuerza de iniciativa para alcanzar la aprobación de los programas y las normas que implementan los programas", a la vez que considera a los decretos de necesidad y urgencia como un dato del derecho constitucional contemporáneo; citado por A. M. Garcia Lema, La reformu por dentro, Buenos Aires, Planeta, 1994. Por su parte Palermo y Novaro, op. cit., sostienen que "La gestión gubernamental en contextos críticos exige a veces medidas cuya efectividad depende de una resolución repentina y no prevista por parte de los sectores afectados. Los decretos de necesidad y urgencia satisfacen este requisito, que desde luego no podría ser cubierto por un tratamiento parlamentario. En ese sentido el gobierno de Menem no innovó...".

(27) Este rol de los medios ha sido por otra parte abundantemente criticado por otras consecuencias negativas para la vida política; G. Sartori, op. cit.

(28) Por ejemplo la obligación del jefe de gabinete de ministros de concurrir mensualmente al Congreso. (29) Cuando un candidato hubiese obtenido al menos el $40 \%$ de los votos y más de 10 puntos de distancia con su inmediato rival, será también considerado ganador y no habrá segunda vuelta. Sobre esta técnica electoral se puede consultar R. Castiglioni, "Ballottage y sistema de partidos: ees el ballottage de Olivos un incentivo para las alianzas?", en: La ciudad futura, $N^{\circ} 40$, Buenos Aires, 1994; y D. A. Sabsay, El sistema de doble vnellu o 'ballollage'; Abeledo-Perrot, s/d.

(30) Al respecto G. Sartori, op. cit.: "With one shot the voter shoots very much in the dark; with two shoots he or she shoots, the second time, in full daylight". Para D. Sabsay y J. M. Onainda, el empleo de este sistema en el contexto de un régimen presidencialista produce resultados negativos, " $\mathrm{El}$ 'ballotage' incorporado a esta mecánica no puede sino exacerbar tanto la concentración del poder en manos presidenciales, como las dificultades para el logro de acuerdos interpartidarios", en: La Constitución de los argentinos, Buenos Aires, Errepar, 1994.

(31) No puede ignorarse los antecedentes del "ballotage" en Argentina, que están asociados a la esperanza de una gran coalición que derrotara al peronismo. Con ese sentido fue incorporado en la reforma constitucional de facto de 1972, pero esa finalidad se vio desbaratada en las elecciones de 1973. (32) Toda nueva mayoria estará tentada de modificar las disposiciones constitucionales que la perjudiquen. Las leyes complementarias que promulgue el Congreso podrian ser ulteriormente derogadas o reformuladas. Ver G. Bidart Campos, Tratado elemental de derecho constitucional argentina, Buenos Aires, Ediar, 1995.

(33) Por cierto los convencionales constituyentes deciden las reformas a introducir por mayoría absoluta, pero han sido especificamente habilitados para ello por una ley del Congreso que requirió los dos tercios de cada una de las Cámaras. Los convencionales sesionan y aprueban un texto que es inmodificable hasta una nueva reforma según el procedimiento especial establecido. En cambio, las leyes complementarias que votaran los legisladores tendrán rango constitucional pero podrán ser derogadas o reformadas indefinidamente por mayoria absoluta.

(34) Refiriéndose a las leyes que deben completar la reforma uno de los principales negociadores del radicalismo las consideraba del modo siguiente: "La exigencia de una votación afirmativa como la indicada (la mayoria absoluta sobre la totalidad de los miembros de cada cámara), difícilmente pueda 
ser cumplida por una sola fuerza política. Esto es, precisamente, el objetivo constitucional: obligar que ciertas decisiones - con permanencia temporal- sean resultantes de un consenso entre varias fuerzas políticas, de modo que ponga a los institutos incluidos en esa clase en una franja de rigidez 'intermedia' porque, con ser una exigencia muy inferior a la necesaria para reformar la Constitución, se ha previsto para la sanción y el cambio de ciertas leyes una rigidez mayor a la ordinaria"; E. Paixao, "La reforma de la administración de justicia. El Consejo de la magistratura", en: H.D. Rosatti et al., La reforma de la Constiturioin, Santa Fe, Rubinzal Culzoni Editores, 1994.

(35) Para Catalina Smulovitz la mencionada flexibilidad crea la posibilidad de reformas autoritarias, "Constitución y poder judicial en la nueva democracia argentina. La experiencia de las instituciones", en: Carlos Acuña (comp.), Ia nunua matriz política angentina, Buenos Aires, Nueva Visión, 1995.

(36) Es la hipótesis que evoca C. Smulovitz quien cita también a G. Molinelli. El propio R. Alfonsin en su reciente Democracia y consenso, op. cit., considera esa posibilidad.

(37) Aun como dato electoral existe un desfazaje entre el arrastre que tuvo su candidatura presidencial respecto al score de sus listas de diputados, diferencia que se acentúa respecto a las candidaturas locales. El radicalismo que fue relegado al tercer puesto en la competencia presidencial, conquistó sin embargo la intendencia en 464 pueblos y ciudades y cinco gobernaciones. La excepción la constituye la Capital Federal donde en varias elecciones consecutivas triunfó la nueva fuerza, y la ciudad de Rosario.

(38) El personalismo se resumia casi exclusivamente en la figura de Chacho Alvarez como encarnación de la nueva fuerza. Esta situación fue variando pero dentro de un esquema de emergencia de personalidades que se disputaban la representación del Frepaso.

(39) La expresión más característica de una estrategia de alianzas con sectores no menemistas del justicialismo involucró a J.O. Bordón, ahora alejado del Frepaso.

(40) Las experiencias contemporáneas indican que ello es posible. Alfonsin al conquistar la posición de paladín de un nuevo orden democrático involucró en primer lugar a los sectores más politizados de la sociedad pero también conquistó por un momento, como consecuencia de ello, a sectores populares más alejados de la circulación política que fueron tocados por la ola de renovación que vivia el país. Menem por su parte, ganó la confianza del establishment a partir de una posición inicial desfavorable, pero en la primera etapa estos sectores permanecieron en la expectativa. En la medida que prosperaron sus planes de estabilización y modernización conquistô su apoyo. Estos mismos sectores fueron reacios al proyecto de reelección hasta que la efectividad politica de la iniciativa los llevó a adherir. 